\title{
Application of an elevated plasma D-dimer cut-off value improves prognosis prediction of advanced non-small cell lung cancer
}

\author{
Chong Chen, Jianhua Li, Jing Li, Xu Wang, Xiaoyan Wang, Na Du, Li Ren \\ Department of Clinical Laboratory, Tianjin Medical University Cancer Institute and Hospital, National Clinical Research Center for Cancer, Key \\ Laboratory of Cancer Prevention and Therapy, Tianjin's Clinical Research Center for Cancer, National Human Genetic Resources Sharing Service \\ Platform, Tianjin, China \\ Contributions: (I) Conception and design: C Chen; (II) Administrative support: L Ren; (III) Provision of study materials or patients: J Li; (IV) \\ Collection and assembly of data: J Li, X Wang, N Du; (V) Data analysis and interpretation: C Chen, X Wang; (VI) Manuscript writing: All authors; \\ (VII) Final approval of manuscript: All authors. \\ Correspondence to: Li Ren. Department of Clinical Laboratory, Tianjin Medical University Cancer Institute and Hospital, National Clinical Research \\ Center for Cancer, Key Laboratory of Cancer Prevention and Therapy, Tianjin's Clinical Research Center for Cancer, National Human Genetic \\ Resources Sharing Service Platform, Tianjin, China. Email: roland-li@163.com.
}

Background: Tumor-related coagulation dysfunction has been reported to be closely associated with poor
prognosis. The present study is aimed to evaluate the prognostic prediction of an elevated plasma D-dimer
cut-off value in advanced non-small cell lung cancer (NSCLC).
Methods: A total of 233 patients initially diagnosed with advanced NSCLC were retrospectively analyzed,
an elevated plasma cut-off value $981 \mathrm{ng} / \mathrm{mL}$ of D-dimer, which was instead of the clinical cut-off value
$500 \mathrm{mg} / \mathrm{mL}$, was used to determine the high and low. Univariate analysis using the Kaplan-Meier method
and log-ranking test, and the multivariate analysis using the Cox proportional hazard regression model were
performed.
Results: Results showed when using the D-dimer value of $500 \mathrm{ng} / \mathrm{mL}$ as an evaluation standard, there was
no significant difference in gender, age, smoking status, histopathology and overall survival rate between
normal D-dimer ( $\leq 500 \mathrm{ng} / \mathrm{mL}$ ) and high D-dimer ( $>500 \mathrm{ng} / \mathrm{mL})$ group. However, when the evaluation
standard for plasma D-dimer was set at $981 \mathrm{ng} / \mathrm{mL}$, the age distribution of the high D-dimer $(>981 \mathrm{ng} / \mathrm{mL}$ )
group was significantly different from the normal D-dimer $(\leq 981 \mathrm{ng} / \mathrm{mL}$ ) group. Moreover, the overall
survival rate in the high D-dimer $(>981 \mathrm{ng} / \mathrm{mL)} \mathrm{group} \mathrm{was} \mathrm{significantly} \mathrm{lower} \mathrm{than} \mathrm{that} \mathrm{in} \mathrm{the} \mathrm{normal} \mathrm{D-dimer}$
( $\leq 981 \mathrm{ng} / \mathrm{mL}$ ) group.

Conclusions: The present study implied that increasing the plasma D-dimer cut-off value to $981 \mathrm{ng} / \mathrm{mL}$ is more beneficial to prognosis prediction in advanced NSCLC.

Keywords: Elevated plasma D-dimer cut-off value; pretreatment D-dimer; overall survival; advanced non-small cell lung cancer (NSCLC)

Submitted Jul 07, 2020. Accepted for publication Sep 04, 2020.

doi: 10.21037/atm-20-5947

View this article at: http://dx.doi.org/10.21037/atm-20-5947

\section{Introduction}

The progression of cancer is strongly associated with the function of the coagulation-fibrinolysis system. The coagulation system can be started by cleavage of plasminogen by tissue plasminogen activator. Fibrinolysis system activation can promote the growth and migration of cancer cells and lower the inflammatory cellmediated immune response, thus accelerating cancer progression (1). In patients with non-small cell lung cancer (NSCLC), fibrinolysis system activation also influences 
chemotherapy tolerance. Patients with lung cancer often show a coagulation abnormality state, including venous thromboembolism (VTE) or disseminated intravascular coagulation (DIC) (2). Tumor-related thrombosis has a considerable influence on the prognosis of patients with cancer. Cancer patients with VTE frequently receive longterm anticoagulant therapy before anticancer treatment, which may miss the best time for anticancer treatment, leading to a dissatisfactory treatment effect (3).

Additionally, VTE can increase the risk rate of hemorrhage in cancer patients, thus delaying or interrupting chemotherapy, resulting in an inferior quality of life in patients $(1,4-6)$. Thrombus formation induces non-cancer causes of death in cancer patients and leads to a low survival rate (7). Therefore, early detection of VTE and reasonable anticoagulant therapy have a critical impact on the prognosis of cancer patients. Meanwhile, it is shown that tumor cells and the hemostatic system are highly interconnected in biological research recently. Tumor cells can activate systemic coagulation through multiple pathways and induce hemostatic and fibrinolytic abnormalities, which can lead to cancer, angiogenesis, and metastasis (8).

Plasma D-dimer is a small cross-linked protein generated from fibrin degradation and is an essential indicator of coagulation dysfunction (2,9-11). It has critical implications for the exclusion of cancer-related thrombosis clinically (12). Elevated plasma D-dimer levels were found in gastric cancer, colorectal cancer, lung cancer, and breast cancer patients, and its plasma levels were reported to be closely associated with the prognosis of solid tumors $(2,13)$. The plasma D-dimer levels can be used to predict VTE in cancer patients $(3,14)$. At present, $500 \mathrm{ng} / \mathrm{mL}$ is used as the cutoff screening value of $\mathrm{D}$-dimer to patients with disorders of coagulation. However, it is not clear if that is a suitable cut-off value for NSCLC patients to screen coagulation disorders (15).

In the present study, we analyzed the relationship between plasma D-dimer levels and survival rate in patients with NSCLC and evaluated the clinical value of the elevated plasma D-dimer cut-off value in prognosis prediction of NSCLC. We found the cut-off value for the plasma D-dimer to diagnose VTE is set at $500 \mathrm{ng} / \mathrm{mL}$, and level high diagnostic sensitivity can be achieved but at the cost of specificity. Therefore, increasing the plasma $\mathrm{D}$-dimer cut-off value is of immense value to the prediction of VTE in cancer patients. In our previous study, we found the diagnostic sensitivity and specificity for VTE were remarkably elevated when the plasma D-dimer cutoff value for cancer patients was raised to $981 \mathrm{ng} / \mathrm{mL}$ $(15,16)$. Previous research has shown that elevated platelet (PLT) count, fibrinogen (FIB) level, and D-dimer level are associated with poor prognosis in lung patients, but the results have been inconsistent $(4,17)$. Furthermore, no earlier study has investigated the effect of elevated plasma D-dimer cut-off value on advanced NSCLC prognosis. Therefore, we conducted this study to investigate the application of an elevated plasma D-dimer cut-off value that improves prognosis' prediction of advanced NSCLC.

We present the following article in accordance with the REMARK reporting checklist (available at http://dx.doi. org/10.21037/atm-20-5947).

\section{Methods}

\section{Patient population}

The study included 60 healthy persons and 233 patients with Eastern Cooperative Oncology Group (ECOG) performance scores of $0,1,2$, who were histological- or cytologically-diagnosed advanced NSCLC at Tianjin Medical University Cancer Institute \& Hospital between Oct 2013 and Oct 2019. Inclusion criteria included those (I) with NSCLC at IIIB or IV on initial diagnosis, (II) with complete follow-up data available, and (III) individuals who had not received chemotherapy, radiotherapy, or other treatments before diagnosis. Exclusion criteria included those (I) with secondary tumors other than NSCLC, (II) with diseases including active infection, malnutrition, familial coagulopathy, peripheral vascular disease, thromboembolism, end-stage renal or liver disease, and (III) who received anticoagulants and anti-thrombotic therapy, and those with ECOG performance scores of $3-4$. Sixty healthy subjects were enrolled in the control group. The Ethics Committee approved the study of the Tianjin Medical University Cancer Institute \& Hospital. All procedures performed in this study involving human participants were in accordance with the Declaration of Helsinki (as revised in 2013). All participants supplied their written, informed consent before being studied.

\section{Study design}

The patients were diagnosed with bronchoscopic forceps biopsy, transbronchial biopsy, pleural puncture and 
biopsy, and pathological and cytological examination of the transthoracic needle aspiration biopsy specimens. The disease stage was determined on clinical and physical examination, such as thoracic computed tomography (CT), brain CT, magnetic resonance (MR), abdominal ultrasonography (USG), bone scintigraphy, and PETCT findings. The classification was made according to the tumor, node, metastasis (TNM)-7 staging system (18). Patients with stage IIIB and Stage IV received chemotherapy or chemotherapy and radiotherapy. Since we examined the association between assessment of the post-CT response and coagulation factors, most of our patients had Stage IIIB and Stage IV disease. The following data were extracted from participants' medical records: age, gender, smoking status, histology, pathological stage and laboratory examination results including prothrombin time $(\mathrm{PT})$, plasma $\mathrm{D}$-dimer level, carcinoembryonic antigen (CEA), cytokeratin-19 fragment (CYFRA21-1), lactate dehydrogenase (LDH), and squamous cell carcinoma antigen (SCC). All laboratory examination results were obtained from patients at their first hospitalization when they had not received any surgery or chemotherapy.

The laboratory findings were evaluated on levels of PLT $\left[(100-300) \times 10^{9} / \mathrm{L}\right]$, CEA $(5 \mu \mathrm{g} / \mathrm{L})$, CYFRA21-1 $(3.3 \mu \mathrm{g} / \mathrm{L})$, SCC $(1.5 \mu \mathrm{g} / \mathrm{L})$ and LDH $(250 \mathrm{U} / \mathrm{L})$. And the patients were classified into normal-, low-, and high-level groups on these levels. The information on survival time was obtained from the Death Registry or calls to patients' relatives.

\section{Biochemical tests}

Venous blood samples were drawn for all patients for measurement of serum D-dimer, PT, APTT, INR, and LDH levels. The samples were centrifuged for separation of cells. The D-dimer level was assessed by enzyme-linked fluorescent immunoassay using a mini-VIDAS device (Bio-Mérieux SA, Craponne, France) at the biochemistry laboratory in our hospital.

\section{Statistical analysis}

Data were evaluated using the SPSS software, Version 16 (IBM, Armonk, NY, USA). The Mann-Whitney U-test was used for independent two-group comparisons, and the Kruskal-Wallis test for multiple comparisons. The relations between variables are assessed using a nonparametric correlation method. The Kaplan-Meier survival analysis method assessed the survival time. The survival comparisons were performed using a log-rank test. The Cox regression method was used for factors predicting mortality. A P value of $<0.05$ was considered statistically significant.

\section{Results}

\section{Baseline demographic and clinicopathological characteristics}

We retrospectively analyzed 706 patients, but only 233 patients met the inclusion criteria and were included in this research. The baseline characteristics of the remaining 233 patients are shown in Table 1. There were 163 (69.96\%) men and $70(30.04 \%)$ women among the 233 patients, with a median age of 67 years. Most lung tumors were adenocarcinoma $(53.22 \%)$, followed by squamous cell carcinoma (23.61\%), and other NSCLC (23.18\%). There were $110(47.21 \%)$ patients at stage IIIB and 123 (52.79\%) at stage IV among NSCLC patients. The abnormal proportion of preoperative CEA, CYFRA21-1, SCC, and $\mathrm{LDH}$ values was $62.23 \%, 56.65 \%, 32.62 \%$, and $47.21 \%$, respectively.

\section{Results of coagulation tests in the study and control groups}

The D-dimer $(2,687.22 \mathrm{ng} / \mathrm{mL})$ was statistically higher in the NSCLC group compared with the control group (406.30 $\mathrm{ng} / \mathrm{mL})(\mathrm{P}=0.000)$, but the difference of the PT and INR levels did not achieve any statistical significance $(\mathrm{P}>0.05)$ (Figure 1).

\section{Factors affecting overall survival: by univariate and multivariate analysis}

Univariate analyses were performed using the KaplanMeier method to assess the predictive capacity of each tested variable (Table 2). Sex $(\mathrm{P}=0.001)$, and $\mathrm{D}$-dimer level, the cut-off value of which was $981 \mathrm{ng} / \mathrm{mL}(\mathrm{P}=0.0001)$, is predictive of the OS.

As Table 2 demonstrates, there was no significant difference in median OS between the normal- and highlevel D-dimer groups (22.44 vs. 17.65 months; $\mathrm{P}>0.05$ ) when the cut-off value of the D-dimer was $500 \mathrm{ng} / \mathrm{mL}$. Otherwise, there was a significant difference in median OS between the normal- and high-level D-dimer groups (22.65 vs. 15.42 months; $\mathrm{P}<0.001)$, when the cut-off value of the D-dimer was $981 \mathrm{ng} / \mathrm{mL}$ (Figure 2). 
Table 1 Demographic and other baseline characteristics of the 233 advanced NSCLC patients

\begin{tabular}{|c|c|c|}
\hline Variables & $\mathrm{N}$ & $\%$ \\
\hline \multicolumn{3}{|l|}{ Age } \\
\hline$<60$ years & 78 & 33.48 \\
\hline$\geq 60$ years & 155 & 66.52 \\
\hline \multicolumn{3}{|l|}{ Gender } \\
\hline Male & 163 & 69.96 \\
\hline Female & 70 & 30.04 \\
\hline \multicolumn{3}{|l|}{ Smoking history } \\
\hline Non-smoker & 80 & 34.33 \\
\hline Smoker & 124 & 53.22 \\
\hline Ex-smoker & 29 & 12.45 \\
\hline \multicolumn{3}{|l|}{ ECOG } \\
\hline 0 & 80 & 34.33 \\
\hline 1 & 65 & 27.90 \\
\hline 2 & 88 & 37.77 \\
\hline \multicolumn{3}{|l|}{ Histopathology } \\
\hline Adenocarcinoma & 124 & 53.22 \\
\hline Squamous carcinoma & 55 & 23.61 \\
\hline Others & 54 & 23.18 \\
\hline \multicolumn{3}{|l|}{ Stage } \\
\hline Stage IIIB & 110 & 47.21 \\
\hline Stage IV & 123 & 52.79 \\
\hline \multicolumn{3}{|c|}{ Level of carcinoembryonic antigen (CEA) } \\
\hline Normal & 88 & 37.77 \\
\hline High & 145 & 62.23 \\
\hline \multicolumn{3}{|c|}{ Level of cytokeratin-19 fragment (CYFRA21-1) } \\
\hline Normal & 101 & 43.35 \\
\hline High & 132 & 56.65 \\
\hline \multicolumn{3}{|c|}{ Level of squamous cell carcinoma antigen (SCC) } \\
\hline Normal & 157 & 67.38 \\
\hline High & 76 & 32.62 \\
\hline \multicolumn{3}{|c|}{ Level of lactate dehydrogenase (LDH) } \\
\hline Normal & 123 & 52.79 \\
\hline High & 110 & 47.21 \\
\hline
\end{tabular}

\section{Discussion}

Cancer patients are often accompanied by dysfunction of coagulation and fibrinolysis systems, which could accelerate the progress of the tumor. Especially, hyperfibrinolysis can degrade tumor matrix proteins, which leads to promoting tumor cell invasion and migration. Recent studies have shown that D-dimer is strongly associated with lymph node metastases in NSCLC (19-21). Tumor microenvironment constituted by immune cells and stromal cells with other "niche" cells leads to cancer patients' tumor-associated coagulation abnormalities, including one of the fibrin degradation products, D-dimer, content increases (8). In our prophase research, 711 tumor patients' blood coagulation and fibrinolysis related laboratory index statistical results showed that the relative indexes associated coagulation in tumor patients were different from those in the normal population. However, the cut-off value of $500 \mathrm{ng} / \mathrm{mL}$ D-dimer for screening disorders of coagulation, which may not meet the clinical requirements for screening disorders of coagulation for advanced NSCLC patients. Increasing the cut-off value of the $\mathrm{D}$-dimer to $981 \mathrm{ng} / \mathrm{mL}$ can effectively predict disorders of coagulation in tumor patients (16).

Earlier studies have shown that D-dimer between gender, pathological type, CEA, CYFRA 21-1, and LDH of advanced NSCLC patients with content has no discernible difference. However, age is a crucial factor that affects the D-dimer discretion of NSCLC patients $(15,22)$. Our study found it enhanced the value of the cut-off from 500 to $981 \mathrm{ng} / \mathrm{mL}$. There exist statistical differences in the content of D-dimer among different age groups, but $500 \mathrm{ng} / \mathrm{mL}$ as the cut-off value cannot reflect the correlation between age and D-dimer.

Much research showed that thrombolytic activity is closely related to tumor angiogenesis, metastasis, chemotherapy resistance, and prognosis. NSCLC patients are often accompanied by hypercoagulability and hyperfibrinolysis (8). Previous studies have shown that plasma D-dimer can be used as an essential indicator of progression and lymph node metastasis, and high plasma D-dimer is also a poor prognostic factor for patients with NSCLC cancer (23-25). In this study, it was found that when $500 \mathrm{ng} / \mathrm{mL}$ was used as a cut-off value, there was no significant difference in the survival period of patients with NSCLC in different groups, which indicates that $500 \mathrm{ng} / \mathrm{mL}$ might be lower cut-off value to patients 

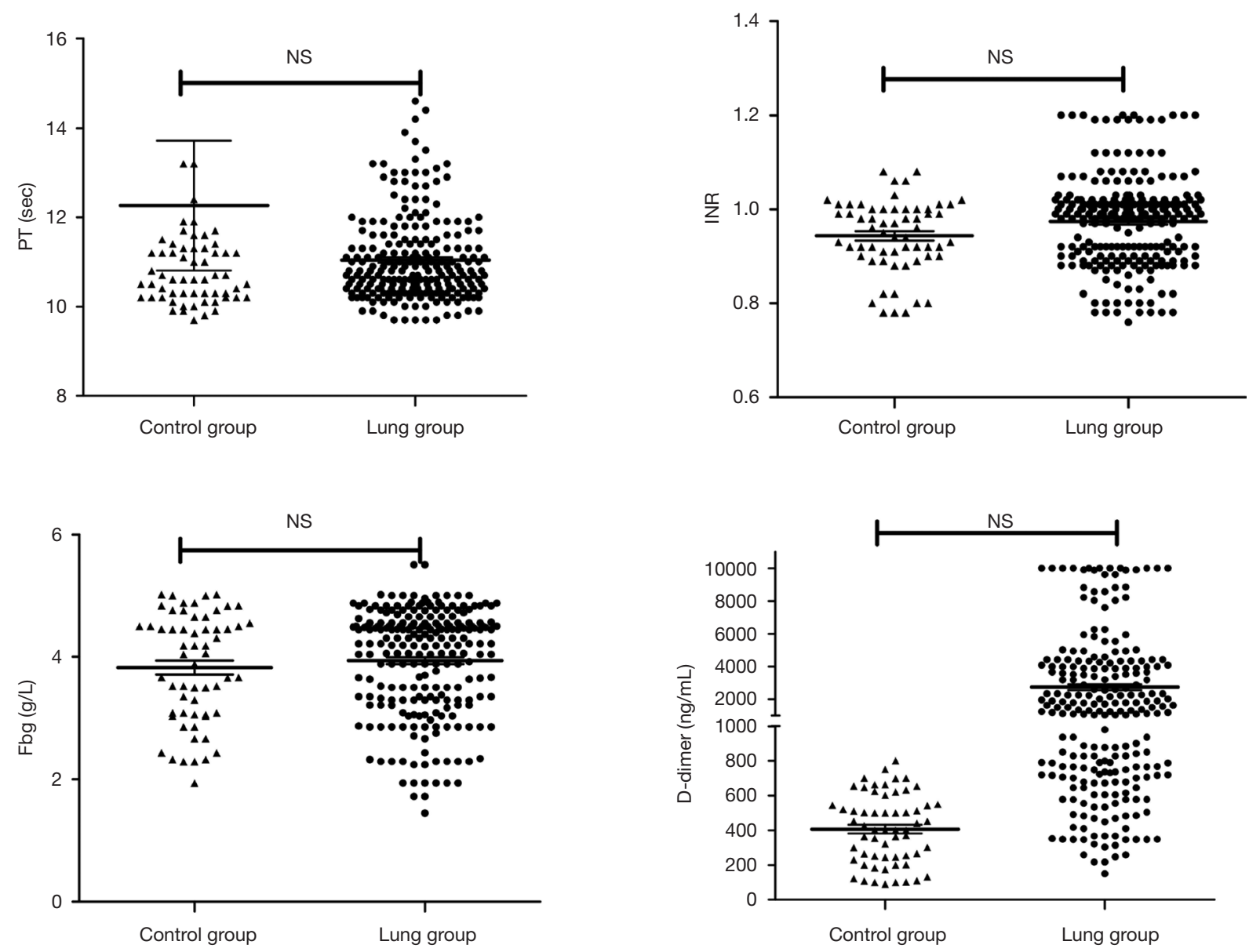

Figure 1 Comparison of coagulation and fibrinolysis indexes between the NSCLC group and normal control group.

with NSCLC. It is unsuitable to correctly distinguish coagulation dysfunction of patients with NSCLC from the normal coagulation states. When the cutoff value of the D-dimer was increased to $981 \mathrm{ng} / \mathrm{mL}$, it was found the survival period of the above group was significantly lower than the below group, and the increase of the cut-off value of the D-dimer to $981 \mathrm{ng} / \mathrm{mL}$ may be an important clinical indicator to evaluate the prognosis of patients with advanced NSCLC.

D-dimer, as the degradation product of fibrinolytic protein, reflects whether the body's internal fibrinolytic system is abnormal, and the high content of d-dimer in plasma is closely related to the poor prognosis of patients with advanced NSCLC (20), breast cancer (26), ovarian cancer (27), pancreatic cancer (28) and colon cancer (29). However, in this study, it was found that the original cut- off value of $500 \mathrm{ng} / \mathrm{mL}$ as D-dimer could not adequately assess the prognosis of advanced NSCLC patients and the enhance of its cut-off value was firmly related to the survival of advanced NSCLC patients. Simultaneously, there was no statistical difference in the survival of advanced NSCLC patients with different CEA, LDH, and CFYR21-1.

\section{Conclusions}

In conclusion, the D-dimer cut-off value increased to $981 \mathrm{ng} / \mathrm{mL}$ after that, which can be used to show whether hyperfibrinolysis exists $(1,13)$. The high content of D-dimer $(>981 \mathrm{ng} / \mathrm{mL})$ is an essential indicator of the poor prognosis of advanced NSCLC patients. Therefore, improving the $\mathrm{D}$-dimer cut-off value can effectively evaluate the prognosis of NSCLC patients. 
Table 2 Univariate analysis of the patient survival according to the clinicopathologic characteristics

\begin{tabular}{|c|c|c|c|}
\hline Variables & Number & $\begin{array}{l}\text { Medium overall } \\
\text { (months) }\end{array}$ & $\mathrm{P}$ \\
\hline \multicolumn{3}{|l|}{ Sex } & 0.001 \\
\hline Male & 163 & 15.84 & \\
\hline Female & 70 & 24.21 & \\
\hline \multicolumn{3}{|l|}{ Age } & 0.192 \\
\hline$<60$ years & 78 & 17.22 & \\
\hline$\geq 60$ years & 155 & 24.50 & \\
\hline \multicolumn{3}{|l|}{ Smoking history } & 0.342 \\
\hline Yes & 109 & 17.43 & \\
\hline No & 124 & 19.20 & \\
\hline \multicolumn{3}{|l|}{ Histology } & 0.034 \\
\hline Adenocarcinoma & 124 & 17.83 & \\
\hline Squamous carcinoma & 55 & 20.39 & \\
\hline Others & 54 & 13.85 & \\
\hline \multicolumn{3}{|c|}{ Carcinoembryonic antigen (CEA) } & 0.129 \\
\hline Normal & 88 & 16.23 & \\
\hline High & 145 & 19.66 & \\
\hline \multicolumn{3}{|c|}{ Cytokeratin-19 fragment (CYFRA21-1) } & 0.286 \\
\hline Normal & 101 & 15.90 & \\
\hline High & 132 & 19.07 & \\
\hline \multicolumn{3}{|c|}{ Squamous cell carcinoma antigen (SCC) } & 0.513 \\
\hline Normal & 157 & 17.92 & \\
\hline High & 76 & 19.40 & \\
\hline \multicolumn{3}{|c|}{ Lactate dehydrogenase (LDH) } & 0.429 \\
\hline Normal & 123 & 19.10 & \\
\hline High & 110 & 17.64 & \\
\hline \multicolumn{3}{|c|}{ D-dimer (cut-off 500 ng/mL) } & 0.102 \\
\hline Normal & 36 & 22.44 & \\
\hline High & 197 & 17.65 & \\
\hline \multicolumn{3}{|c|}{ D-dimer (cut-off 981 ng/mL) } & 0.0001 \\
\hline Normal & 96 & 22.65 & \\
\hline High & 137 & 15.42 & \\
\hline
\end{tabular}

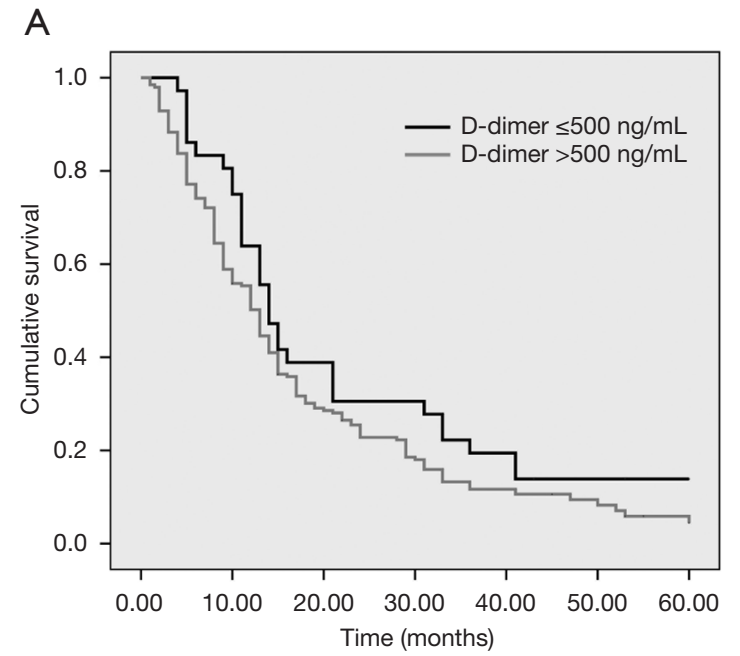

B

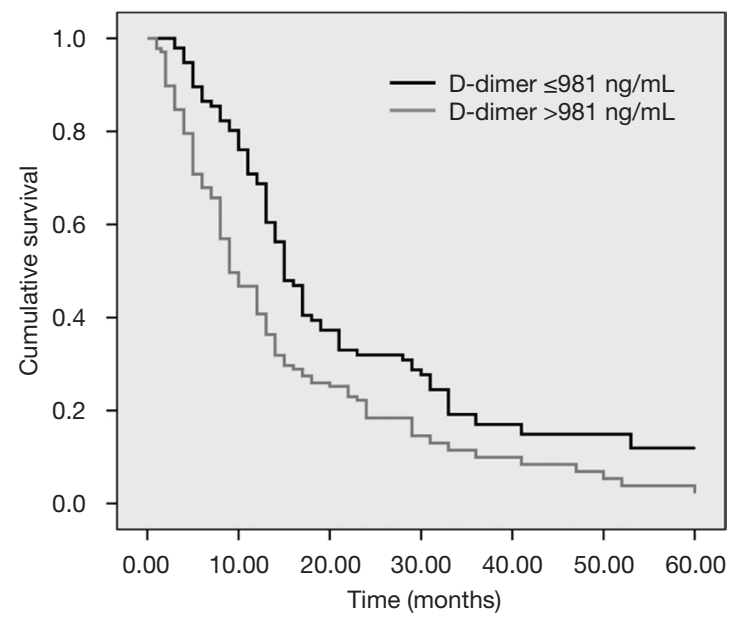

Figure 2 Kaplan-Meier estimates of the survival probabilities between normal and high D-dimer levels. (A) The cut-off value was $500 \mathrm{ng} / \mathrm{mL}$; (B) the cut off value was $981 \mathrm{ng} / \mathrm{mL}$.

\section{Acknowledgments}

Funding: This study was supported by the Science \& Technology Development Fund of Tianjin Education Commission for Higher Education (project number: 2018KJ048, to Chen).

\section{Footnote}

Reporting Checklist: The authors have completed the REMARK reporting checklist. Available at http://dx.doi. 
org/10.21037/atm-20-5947

Data Sharing Statement: Available at http://dx.doi. org/10.21037/atm-20-5947

Conflicts of Interest: All authors have completed the ICMJE uniform disclosure form (available at http://dx.doi. org/10.21037/atm-20-5947). The authors have no conflicts of interest to declare.

Ethical Statement: The authors are accountable for all aspects of the work in ensuring that questions related to the accuracy or integrity of any part of the work are appropriately investigated and resolved. All procedures performed in this study involving human participants were in accordance with the Declaration of Helsinki (as revised in 2013). The Ethics Committee approved the study of the Tianjin Medical University Cancer Institute \& Hospital. All participants supplied their written, informed consent before being studied.

Open Access Statement: This is an Open Access article distributed in accordance with the Creative Commons Attribution-NonCommercial-NoDerivs 4.0 International License (CC BY-NC-ND 4.0), which permits the noncommercial replication and distribution of the article with the strict proviso that no changes or edits are made and the original work is properly cited (including links to both the formal publication through the relevant DOI and the license). See: https://creativecommons.org/licenses/by-nc-nd/4.0/.

\section{References}

1. Hisada Y, Mackman N. Cancer-associated pathways and biomarkers of venous thrombosis. Blood 2017;130:1499-506.

2. Louneva N, Maity A, Kennedy AR. Plasma D-Dimer Levels are Elevated in Radiation Oncology Patients. Radiat Res 2020;193:46-53.

3. Patel P, Patel P, Bhatt M, et al. Systematic review and meta-analysis of outcomes in patients with suspected deep vein thrombosis. Blood Adv 2020;4:2779-88.

4. Hanna DL, White RH, Wun T. Biomolecular markers of cancer-associated thromboembolism. Crit Rev Oncol Hematol 2013;88:19-29.

5. Hisada Y, Geddings JE, Ay C, et al. Venous thrombosis and cancer: from mouse models to clinical trials. J Thromb Haemost 2015;13:1372-82.

6. Abdol Razak NB, Jones G, Bhandari M, et al. Cancer-
Associated Thrombosis: An Overview of Mechanisms, Risk Factors, and Treatment. Cancers (Basel) 2018;10:380.

7. Fei X, Wang H, Jiang L, et al. Clinical and Prognostic Significance of Lupus Anticoagulant Measurement in Patients With Lung Cancer. Technol Cancer Res Treat 2017;16:1006-13.

8. Mukai M, Oka T. Mechanism and management of cancerassociated thrombosis. J Cardiol 2018;72:89-93.

9. Schorling RM, Pfrepper C, Golombek T, et al. Evaluation of Biomarkers for the Prediction of Venous Thromboembolism in Ambulatory Cancer Patients. Oncol Res Treat 2020;43:414-27.

10. Moik F, Zöchbauer-Müller S, Posch F, et al. Systemic Inflammation and Activation of Haemostasis Predict Poor Prognosis and Response to Chemotherapy in Patients with Advanced Lung Cancer. Cancers (Basel) 2020;12:1619.

11. Sikora-Skrabaka M, Skrabaka D, Ruggeri P, et al. D-dimer value in the diagnosis of pulmonary embolism-may it exclude only? J Thorac Dis 2019;11:664-72.

12. Lin Y, Liu Z, Qiu Y, et al. Clinical significance of plasma D-dimer and fibrinogen in digestive cancer: A systematic review and meta-analysis. Eur J Surg Oncol 2018;44:1494-503.

13. Deng HY, Zheng X, Jiang R, et al. Preoperative D-dimer level is an independent prognostic factor for non-small cell lung cancer after surgical resection: a systematic review and meta-analysis. Ann Transl Med 2019;7:366.

14. Cho JH, Kim JB, Lee DG. Correlation Between D-Dimer Level and Deep Venous Thrombosis in Patients With Acute Spinal Cord Injuries. Am J Phys Med Rehabil 2020;99:613-6.

15. Nybo M, Hvas AM. Age-adjusted D-dimer cut-off in the diagnostic strategy for deep vein thrombosis: a systematic review. Scand J Clin Lab Invest 2017;77:568-73.

16. Chen C, Li G, Liu YD, et al. A new D-dimer cutoff value to improve the exclusion of deep vein thrombosis in cancer patients. Asian Pac J Cancer Prev 2014;15:1655-8.

17. Hou C, Jiang F, Ma H, et al. Prognostic role of preoperative platelet, fibrinogen, and $\mathrm{D}$-dimer levels in patients with non-small cell lung cancer: A multicenter prospective study. Thorac Cancer 2019;10:304-11.

18. Mengoli MC, Longo FR, Fraggetta F, et al. The 2015 World Health Organization Classification of lung tumors: new entities since the 2004 Classification. Pathologica 2018;110:39-67.

19. Gao XL, Wang SS, Cao DB, et al. The role of plasma D-dimer levels for predicting lymph node and mediastinal lymph node involvement in non-small cell lung cancer. 
Clin Respir J 2018;12:2151-6.

20. Fan S, Zhao G, An G. High pretreatment plasma D-dimer levels are associated with shorter overall survival in patients with small cell lung cancer. J Int Med Res 2019;47:215-24.

21. Mahé I, Elalamy I, Gerotziafas GT, Girard P. Treatment of Cancer-Associated Thrombosis: Beyond HOKUSAI. TH Open 2019;3:e309-15.

22. Parks C, Bounds R, Davis B, et al. Investigation of ageadjusted D-dimer using an uncommon assay. Am J Emerg Med 2019;37:1285-8.

23. Wang Y, Wang Z. Predictive value of plasma D-dimer levels in patients with advanced non-small-cell lung cancer. Onco Targets Ther 2015;8:805-8.

24. Jiang X, Mei X, Wu H, et al. D-dimer level is related to the prognosis of patients with small cell lung cancer. Ann Transl Med 2017;5:394.

25. Zhang C, Jia Y, Jia Y, et al. Prognostic and predictive value of plasma D-dimer levels in patients with small-cell lung

Cite this article as: Chen C, Li J, Li J, Wang X, Wang X, Du N, Ren L. Application of an elevated plasma D-dimer cut-off value improves prognosis prediction of advanced non-small cell lung cancer. Ann Transl Med 2020;8(18):1153. doi: 10.21037/atm20-5947 cancer. Int J Clin Oncol 2018;23:1070-5.

26. Ghadhban BR. Plasma d-dimer level correlated with advanced breast carcinoma in female patients. Ann Med Surg (Lond) 2018;36:75-8.

27. Chen L, Wang X, Shu J, et al. Diagnostic value of serum D-dimer, CA125, and neutrophil-to-lymphocyte ratio in differentiating ovarian cancer and endometriosis. Int J Gynaecol Obstet 2019;147:212-8.

28. Durczynski A, Kumor A, Hogendorf P, et al. Preoperative high level of D-dimers predicts unresectability of pancreatic head cancer. World J Gastroenterol 2014;20:13167-71.

29. Tekeşin K, Bayrak S, Esatoğlu V, et al. D-Dimer and Carcinoembryonic Antigen Levels: Useful Indicators for Predicting the Tumor Stage and Postoperative Survival. Gastroenterol Res Pract 2016;2016:4295029.

(English Language Editor: J. Chapnick) 